\title{
Anal Hemorrhage, CTCAE
}

National Cancer Institute

\section{Source}

National Cancer Institute. Anal Hemorrhage, CT CAE. NCI Thesaurus. Code C143276.

A disorder characterized by bleeding from the anal region. 